TAPROBANICA, ISSN 1800-427X. October, 2012. Vol. 04, No. 02: pp. 60-64.

(C) Taprobanica Private Limited, 146, Kendalanda, Homagama, Sri Lanka.

\title{
EDITORIAL
}

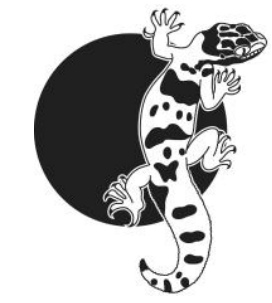

\section{Meet the Parasites: genetic approaches uncover new insights in parasitology}

With the continual refinement and development of new molecular approaches, the last few years have witnessed a dramatic increase in the number of parasitological studies using genetics to answer ecological questions. Particularly, the advent of full genome sequencing holds promise to "decode all life", offering new potential to not only understand, but cure diseases (Butler, 2010). With the over-abundance of information and the comparable rapidity that these approaches can provide data, ecologists must be more careful than ever to select tools that suit their objectives and provide the resolution to their data that best fits their question, not simply the most attractive option. In this vein, Weinberg (2010) acknowledges that the molecular revolution has allowed a new mentality of "discover now and explain later" to invade research, and this has placed hypothesis-driven research under threat. However, regardless of potential setbacks that molecular approaches have introduced into basic research, their contributions to the progression of science are unquestionably more numerous and far reaching. Here, we discuss six areas where molecular approaches are useful to ecological parasitologists.

\section{Increase the Resolution of Parasite Identification}

Perhaps most obviously, molecular approaches allow researchers to sub-type parasites and identify cryptic taxa. These approaches are extremely valuable when morphological features traditionally used to identify parasite taxa are limited, as is often the case. DNA-based approaches allow for a direct evaluation of an organism's genome, irrespective of environment or ontogeny, and provide absolute rather than relative data (McManus \& Bowles, 1996). This is particularly important in parasites, where morphologically distinguishable life stages, such as adults, may be unavailable to researchers, such as when hosts are endangered or otherwise protected from invasive sampling (Criscione et al., 2005). Molecular approaches are also useful in uncovering cryptic parasite diversity - for example, ribosomal DNA sequencing to identify that human and pig whipworm infections were caused by separate species (Cutillas et al., 2009), or mitochondrial DNA sequencing to uncover multiple cryptic avian malaria parasites (Bensch et al., 2004).

\section{Discover New Parasites}

The recent advent of next generation high-throughput sequencing platforms has revolutionized the way scientists discover pathogens. Previous technology, such as degenerate PCR, immunoscreening of cDNA libraries, and microarrays (Wang et al., 2003) provide opportunity to identify new pathogens from existing families. More recently, panmicrobial oligonucleotide arrays (Greenechips) use oligonucleotides affixed to a glass slide that represent a diversity of vertebrate pathogens, including viruses, bacteria, fungi, and helminths, to specifically identify pathogens genetically similar to those on the chip (Palacios et al., 2007). While still appropriate in many instances, these technologies are still limited by availability of information novel, highly divergent, or low parasitaemia/titre pathogens stand little chance of discovery (Kreuze et al., 2009). Massively parallel approaches circumvent this problem, and have been successful in uncovering and cataloging the diversity (Liu et al., 2009; Manske et al., 2012), divergence (Lauck et al., 2011), and evolution of pathogens (Qi et al., 2009).

\section{Infer Parasite Transmission}

Molecular approaches may also be used to infer how parasites are transmitted, either within or between host species. Within host species, molecular approaches can be used to elucidate how a parasite's biology may affect its transmission (Mackinnon \& Read, 1999) or how parasite strains are transmitted in a host population (Anderson et al., 1995). Interestingly, genetics have also been used to identify transmission heterogeneities or susceptible demographics in a host species. For example, using microsatellites and random amplified polymorphic DNA (RAPD), Prugnolle et al. (2002) discovered sex-specific genetic structuring of 
Schistosoma mansoni, with less genetic differentiation in male hosts than in female hosts. Between host species, direct PCR and sequencing and RAPD, respectively, have been used to identify cross-species transmission of avian blood parasites (Waldenström et al., 2002) and primate nodular worms (de Gruijter et al., 2004) in complex communities where host specificity was not possible to determine through morphological comparison. Further, with several influential publications suggesting that the number of emerging infectious diseases have rapidly increased in recent times (Daszak et al., 2000; Jones et al., 2008), and that many, such as HIV-1 (Gao et al., 1999) and HIV-2 (Gao et al., 1992; Wertheim \& Worobey, 2009b), influenza (Subbarao et al., 1998; Webster et al., 2006), and Ebola (Leroy et al., 2009) are caused by zoonotic pathogens (i.e., pathogens transmissible from wildlife to humans), researchers have turned to molecular approaches to uncover transmission events from wildlife to humans. For example, Wolfe et al. (2004) demonstrated that bushmeat hunters in direct contact with wild non-human primate body fluids were infected with simian foamy viruses arising from three different non-human primate species, which suggests that human contact with wildlife has allowed these retroviruses to actively cross into human populations.

Finally, a re-emerging discipline, spatial epidemiology, considers how transmission is affected by space (Ostfeld et al., 2005). In considering landscape, this discipline can track the movement of hosts and parasites over different spatial scales, and therefore identify where and why parasites move across heterogeneous environments. Research in this field has effectively identified barriers to the transmission of infectious diseases, and can be used to predict the evolution and spread of pathogens, as well as the susceptibility of interconnected host populations (Archie et al., 2009; Smith et al., 2002). While the addition of genetics to spatial epidemiology has been rare to date, it has allowed researchers to resolve the mechanisms behind adaptive differentiation and parasite evolution in the context of a landscape. For example, Biek et al. (2007) used genetic approaches to reconstruct the spatial and demographic spread of rabies virus following its introduction into a susceptible population.

\section{Identify Disease Origins}

Not only can molecular approaches be used to understand the phylogenetic relationships among extant parasites, but they can be used to infer their origins. The origins of some of the world's most serious infectious diseases have now been determined, such as HIV-1 (Gao et al., 1999) and Plasmodium falciparum. In the case of the latter, Liu et al. (2010) collected feces from chimpanzees (Pan troglodytes), western gorillas (Gorilla gorilla), eastern gorillas (Gorilla beringei), and bonobos (Pan paniscus) to isolate Plasmodium and identify the origins of the most pathogenic form of human malaria, P. falciparum. Their results show that $P$. falciparum is nearly identical to isolates from western gorillas and that these species form a monophyletic group. This suggests that human $P$. falciparum likely arose via a single jump from western gorillas to humans. This example not only provides evidence for how one may use molecular approaches to identify the origins of parasites, but also highlights how the continual improvement of molecular methods, such as from conventional (bulk) PCR (Escalante et al., 1995; Rich et al., 2009), to single genome amplification (which dilutes template DNA to avoid the generation of recombinants during PCR), may not only increase resolution, but change the interpretation of results. Finally, genetic information can also be used to determine time since divergence and rate of evolution of a given parasite. For example, Wertheim \& Worobey (2009) used a Bayesian relaxed molecular clock to date the ages of the SIV lineages that gave rise to HIV-1 and 2. Results suggest that the SIV lineage is surprisingly young for a retrovirus, and that the HIV-1 group M and N share a most recent common ancestor with SIVcpz, its progenitor, in 1853 and 1921 - a useful estimate of when this virus may have jumped into human populations.

\section{Understand Virulence}

The majority of laboratory-based studies in parasitology attempt to understand parasite virulence. Genetic approaches that elucidate variations in parasite strain (Mackinnon \& Read, 1999) and host immunological factors (Merrick et al., 2012) are both essential to understanding parasite virulence, and have been instrumental in the success of this burgeoning field (Pedersen \& Babayan, 2011). Recently, studies of coinfection, which examine the result of multiple parasites invading a single host and the corresponding immunological response, have garnered interest. One of the first to examine co-infection in populations of wild animals was Ezenwa et al. (2010), who demonstrated that helminth infection in African buffalo (Syncerus caffer) facilitates tuberculosis infection by supressing the microparasitic Th1 response. 


\section{Elucidate Host Ecology}

While many researchers have used host ecology (e.g., behaviour, habitat use, foraging strategy) to explain parasite genetic diversity, we can also use parasite genetic diversity to explain host ecology. Mackenzie (2002) reviews how parasites can be used as biological tags in a variety of marine organisms, since populations of a given species that experience different environmental conditions may acquire specific parasites that can then be used for identification and tracking. Indeed, research by Criscione et al. (2006) determined that genotyping the trematode parasites of steelhead trout (Oncorhynchus mykiss) was four times more effective in correctly assigning the fish to its population of origin than genotyping the fish itself. In terrestrial systems, pathogens such as the gastric bacterium Helicobacter pylori have been used to track human migration through sequencing strain variation that replicate colonization events. The use of parasites as tags has also recently been applied to wildlife populations. Biek et al. (2006) suggests that rapidly evolving viruses are a useful tool in studying the population dynamics of their hosts. Using feline immunodeficiency virus (FIV), they constructed the spatial ranges of the host (Puma concolor) in more detail than host microsatellite analysis of the host could uncover. This suggests that such rapidly evolving parasites are useful in characterising host population dynamics in what they termed "shallow" time.

\section{Conclusions}

While not being exhaustive, we have tried to highlight key ways in which natural historians and ecologists can use genetic approaches to increase the resolution with which they can answer their questions. Pairing and collaboration between field and molecular experts is becoming more and more frequent, and we believe this to be a significant step forward in understanding parasitology in complex ecosystems.

\section{Acknowledgements}

We gratefully acknowledge the thoughts and suggestions provided by D. R. Mills and T. L. Goldberg on this editorial.

\section{Literature cited}

Anderson, T. J. C., M. E. Romero-Abal and J. Jaenike, 1995. Mitochondrial DNA and Ascaris microepidemiology: the composition of parasite populations from individual hosts, families and villages. Parasitology, 110: 221-229.

Archie, E. A., G. Luikart and V. O. Ezenwa, 2009. Infecting epidemiology with genetics: a new frontier in disease ecology. Trends in Ecology \& Evolution, 24: 21-30.

Bensch, S., J. Péarez-Tris, J. Waldenströum and O. Hellgren, 2004. Linkage between nuclear and mitochondrial DNA sequences in avian malaria parasites: multiple cases of cryptic speciation? Evolution, 58: 1617-1621.

Biek, R., A. J. Drummond and M. Poss, 2006. A Virus Reveals Population Structure and Recent Demographic History of Its Carnivore Host. Science, 311: 538-541.

Biek, R., J. C. Henderson, L. A.Waller, C. E. Rupprecht and L. A. Real, 2007. A high-resolution genetic signature of demographic and spatial expansion in epizootic rabies virus. Proceedings of the National Academy of Sciences, 104: 7993-7998.

Butler, D., 2010. Human genome at ten: Science after the sequence. Nature, 465: 1000-1001.

Criscione, C. D., R. Poulin and M. S. Blouin, 2005. Molecular ecology of parasites: elucidating ecological and microevolutionary processes. Molecular Ecology, 14: 2247-2257.

Criscione, C. D., B. Cooper and M. S. Blouin, 2006. Parasite Genotypes Identify Source Populations of Migratory Fish More Accurately than Fish Genotypes. Ecology, 87: 823-828.

Cutillas, C., R. Callejon, M. de Rojas, B. Tewes, J. M. Ubeda, C. Ariza and D. C. Guevara, 2009. Trichuris suis and Trichuris trichiura are different nematode species. Acta Tropica, 111: 299-307.

Daszak, P., A. A. Cunningham and A. D. Hyatt, 2000. Emerging Infectious Diseases of Wildlife- Threats to Biodiversity and Human Health. Science, 287: 443-449. 


\section{EDITORIAL}

de Gruijter, J. M., J. Ziem, J. J. Verweij, A. M. Polderman and R. B. Gasser, 2004. Genetic substructuring within Oesophagostomum bifurcum (Nematoda) from human and non-human primates from Ghana based on random amplified polymorphic DNA analysis. American Journal of Tropical Medicine and Hygiene, 71: 227-233.

Escalante, A. A., E. Barrio and F. J. Ayala, 1995. Evolutionary origin of human and primate malarias: evidence from the circumsporozoite protein gene. Molecular Biology and Evolution, 12: 616-626.

Ezenwa, V. O., Etienne, S. Rampal, L. Gordon, A. Beja-Pereira and A. E. Jolles, 2010. Hidden Consequences of Living in a Wormy World: Nematode-Induced Immune Suppression Facilitates Tuberculosis Invasion in African Buffalo. The American Naturalist, 176: 613-624.

Gao, F., L. Yue, A. T. White, P. G. Pappas, J. Barchue, A. P. Hanson, B. M. Greene, P. M. Sharp, G. M. Shaw and B. H. Hahn, 1992. Human infection by genetically diverse SIVSM-related HIV-2 in West Africa. Nature, 358: 495-499.

Gao, F., E. Bailes, D. L. Robertson, Y. Chen, C. M. Rodenburg, S. F. Michael, L. B. Cummins, L. O. Arthur, M. Peeters, G. M. Shaw, P. M. Sharp and B. H. Hahn, 1999. Origin of HIV-1 in the chimpanzee Pan troglodytes troglodytes. Nature, 397: 436-441.

Jones, K. E., N. G. Patel, M. A. Levy, A. Storeygard, D. Balk, J. L. Gittleman and P. Daszak, 2008. Global trends in emerging infectious diseases. Nature, 451: 990-993.

Kreuze, J.F., A. Perez, M. Untiveros, D. Quispe, S. Fuentes, I. Barker and R. Simon, 2009. Complete viral genome sequence and discovery of novel viruses by deep sequencing of small RNAs: A generic method for diagnosis, discovery and sequencing of viruses. Virology, 388: 1-7.

Lauck, M., D. Hyeroba, A. Tumukunde, G. Weny, S. M. Lank, C. A. Chapman, D. H. O'Connor, T. C. Friedrich and T. L. Goldberg, 2011. Novel, Divergent Simian Hemorrhagic Fever Viruses in a Wild Ugandan Red Colobus Monkey Discovered Using Direct Pyrosequencing. Plos One, 6: e19056.

Leroy, E. M., A. Epelboin, V. Mondonge, X. Pourrut, J. -P. Gonzalez, M. -T. Jean-Jaques and P. Formente, 2009. Human Ebola Outbreak Resulting from Direct Exposure to Fruit Bats in Luebo, Democratic Republic of Congo, 2007. Vector-Borne and Zoonotic Diseases, 9: 723-728.

Liu, J. M., J. Livny, M. S. Lawrence, M. D. Kimball, M. K. Waldor and A. Camilli, 2009. Experimental discovery of sRNAs in Vibrio cholerae by direct cloning, 5S/tRNA depletion and parallel sequencing. Nucleic Acids Research, 37: e46.

Mackenzie, K., 2002. Parasites as biological tags in population studies of marine organisms: an update. Parasitology, 124: 153-163.

Mackinnon, M. J. and A. F. Read, 1999. Genetic Relationships between Parasite Virulence and Transmission in the Rodent Malaria Plasmodium chabaudi. Evolution, 53: 689-703.

Manske, M., O. Miotto, S. Campino, S. Auburn, J. Almagro-Garcia, G. Maslen, J. O'Brien, A. Djimde, O. Doumbo, I. Zongo, J. -B. Ouedraogo, P. Michon, I. Mueller, P. Siba, A. Nzila, S. Borrmann, S. M. Kiara, K. Marsh, H. Jiang, X. -Z. Su, C. Amaratunga, R. Fairhurst, D. Socheat, F. Nosten, M. Imwong, N. J. White, M. Sanders, E. Anastasi, D. Alcock, E. Drury, S. Oyola, M. A. Quail, D. J. Turner, V. Ruano-Rubio, D. Jyothi, L. Amenga-Etego, C. Hubbart, A. Jeffreys, K. Rowlands, C. Sutherland, C. Roper, V. Mangano, D. Modiano, J. C. Tan, M. T. Ferdig, A. Amambua-Ngwa, D. J. Conway, S. Takala-Harrison, C. V. Plowe, J. C. Rayner, K. A. Rockett, T. G. Clark, C. I. Newbold, M. Berriman, B. MacInnis and D. P. Kwiatkowski, 2012. Analysis of Plasmodium falciparum diversity in natural infections by deep sequencing. Nature advance online publication.

McManus, D. P. and J. Bowles, 1996. Molecular genetic approaches to parasite identification: their value in diagnostic parasitology and systematics. International Journal for Parasitology, 26: 687-704.

Merrick, C. J., C. Huttenhower, C. Buckee, A. Amambua-Ngwa, N. Gomez-Escobar, M. Walther, D. J. Conway and M. T. Duraisingh, 2012. Epigenetic dysregulation of virulence gene expression in severe Plasmodium falciparum malaria. Journal of Infectious Disease, 205: 1593-1600. 


\section{EDITORIAL}

Ostfeld, R.S., G. E. Glass and F. Keesing, 2005. Spatial epidemiology: an emerging (or re-emerging) discipline. Trends in Ecology and Evolution, 20: 328-336.

Palacios, G., Q. Phenix-Lan, O. J. Jabado, S. Conlan, D. L. Hirschberg, L. Yang, Z. Junhui, N. Renwick, J. Hui, H. Hegyi, A. Grolla, J. E. Strong, J. S. Towner, T. W. Geisbert, P. B. Jahrling, C. Büchen-Osmond, H. Ellerbrok, M. P. Sanchez-Seco, Y. Lussier and P. Formenty, 2007. Panmicrobial Oligonucleotide Array for Diagnosis of Infectious Diseases. Emerging Infectious Diseases, 13: 73-81.

Pedersen, A. B. and S. A. Babayan, 2011. Wild immunology. Molecular Ecology, 20: 872-80.

Prugnolle, F., T. De Meeûs, P. Durand, C. Sire and A. Théron, 2002. Sex-specific genetic structure in Schistosoma mansoni: evolutionary and epidemiological implications. Molecular Ecology, 11: 1231-1238.

Qi, W., M. Käser, K. Röltgen, D. Yeboah-Manu and G. Pluschke, 2009. Genomic Diversity and Evolution of Mycobacterium ulcerans Revealed by Next-Generation Sequencing. Plos Pathog, 5: e1000580.

Rich, S. M., F. H. Leendertz, G. Xu, M. LeBreton, C. F. Djoko, M. N. Aminake, E. E. Takang, J. L. Diffo, B. L. Pike, B. M. Rosenthal, P. Formenty, C. Boesch, F. J. Ayala and N. D. Wolfe, 2009. The origin of malignant malaria. Proceedings of the National Academy of Science USA, 106: 14902-14907.

Smith, D. L., B. Lucey, L. A. Waller, J. E. Childs and L. A. Real, 2002. Predicting the Spatial Dynamics of Rabies Epidemics on Heterogeneous Landscapes. Proceedings of the National Academy of Sciences USA, 99: 3668-3672.

Subbarao, K., A. Klimov, J. Katz, H. Regnery, W. Lim, H. Hall, M. Perdue, D. Swayne, C. Bender, J. Huang, M. Hemphill, T. Rowe, M. Shaw, X. Xu, K. Fukuda and N. Cox, 1998. Characterization of an Avian Influenza A (H5N1) Virus Isolated from a Child with a Fatal Respiratory Illness. Science, 279: 393-396.

Waldenström, J., S. Bensch, S. Kiboi, D. Hasselquist and U. Ottosson, 2002. Cross-species infection of blood parasites between resident and migratory songbirds in Africa. Molecular Ecology, 11: 1545-1554.

Wang, D., A. Urisman, Y. -T. Liu, M. Springer, T. G. Ksiazek, D. D. Erdman, E. R. Mardis, M. Hickenbotham, V. Magrini, J. Eldred, J. P. Latreille, R. K. Wilson, D. Ganem and J. L. DeRisi, 2003. Viral Discovery and Sequence Recovery Using DNA Microarrays. Plos Biology, 1: e2.

Webster, R. G., M. Peiris, H. L. Chen and Y. Guan, 2006. H5N1 outbreaks and enzootic influenza. Emerging Infectious Diseases, 12: 3-8.

Weinberg, R., 2010. Point: Hypotheses first. Nature, 464: 678-678.

Wertheim, J. O. and M. Worobey, 2009. Dating the Age of the SIV Lineages That Gave Rise to HIV-1 and HIV2. PLos Computational Biology, 5: e1000377.

Wolfe, N. D., W. M. Switzer, J. K. Carr, V. B. Bhullar, V. Shanmugam, U. Tamoufe, A. T. Prosser, J. N. Torimiro, A. Wright, E. Mpoudi-Ngole, F. E. McCutchan, D. L. Birx, T. M. Folks, D. S. Burke and W. Heneine, 2004. Naturally acquired simian retrovirus infections in central African hunters. The Lancet, 636: 932-937.

Ria R. Ghai ${ }^{1} \&$ Colin A. Chapman ${ }^{2 *}$

"Sectional Editor: Taprobanica, the journal of Asian Biodiversity

August $12^{\text {th }}, 2012$

${ }^{1}$ Department of Biology, McGill University

1205 Docteur Penfield, Montreal, Quebec, H3A 1B1

CANADA

${ }^{2}$ McGill School of Environment \& Department of Anthropology

McGill University, Montreal, Quebec, H3A 2T7

CANADA 